\title{
Drug Rash with Eosinophilia and Systemic Symptoms: Two Emergency Department Cases
}

\section{Citation}

Tsyrulnik, Alina, and Adam B. Landman. 2011. Drug rash with eosinophilia and systemic symptoms: Two emergency department cases. Western Journal of Emergency Medicine 12(4): $559-562$.

\section{Published Version}

doi:10.5811/westjem.2010.11.2077

\section{Permanent link}

http://nrs.harvard.edu/urn-3:HUL.InstRepos:9696328

\section{Terms of Use}

This article was downloaded from Harvard University's DASH repository, and is made available under the terms and conditions applicable to Other Posted Material, as set forth at http:// nrs.harvard.edu/urn-3:HUL.InstRepos:dash.current.terms-of-use\#LAA

\section{Share Your Story}

The Harvard community has made this article openly available.

Please share how this access benefits you. Submit a story.

\section{Accessibility}




\section{Drug Rash with Eosinophilia and Systemic Symptoms: Two Emergency Department Cases}

\author{
Alina Tsyrulnik, MD* \\ Adam Landman, $\mathrm{MD}^{\dagger}$
}

\author{
* Yale University School of Medicine, Department of Emergency Medicine, New \\ Haven, Connecticut \\ † Brigham and Women's Hospital, Department of Emergency Medicine and Harvard \\ Medical School, Boston, Massachusetts
}

Supervising Section Editor: Rick A. McPheeters, DO

Submission history: Submitted August 26, 2010; Accepted November 24, 2010

Reprints available through open access at http://escholarship.org/uc/uciem_westjem

DOI: 10.5811/westjem.2010.11.2077

Drug rash with eosinophilia and systemic symptoms (DRESS) is a rare, severe adverse drug event that appears with a generalized rash, fevers, and dysfunction of 1 or more organ systems. We describe 2 patients ( 1 adult and 1 pediatric) seen in the emergency department with DRESS, and review the clinical presentations, potential complications, and management of DRESS. Although rare, it can be associated with significant morbidity, including liver failure and death, and should be considered in the differential diagnosis of patients with diffuse rash and systemic symptoms. [West J Emerg Med. 2011;12(4):559-562.]

\section{INTRODUCTION}

Drug rash with eosinophilia and systemic symptoms (DRESS) syndrome is a life-threatening adverse drug reaction that is distinct from other drug-related reactions. Patients with DRESS present with generalized rash, fever and internal organ involvement weeks to months after initiation of several known medications. Characteristic laboratory findings include eosinophilia and/or atypical lymphocytes, in addition to evidence of organ dysfunction. ${ }^{1,2}$ Prompt recognition of this disorder is important because the mortality is $10 \%$, but can be up to $40 \%$ if organ failure is present. ${ }^{3}$

Although DRESS is well described in the dermatology literature, no case reports have been published in emergency medicine literature. Given the potential morbidity, wide differential diagnoses, and relatively simple treatment, it is important for emergency physicians to consider this entity in patients with severe rashes. In this case report, we present an adult and a pediatric emergency department (ED) patient with DRESS, and review the presentation, potential complications, and management of DRESS.

\section{CASE ONE}

A 27-year-old man appeared in the ED complaining of a whole-body rash, pruritis, and fevers. The patient had 2 recent admissions to the hospital. Six weeks earlier, he was assaulted and sustained a skull fracture with a subdural hematoma that was managed surgically. At that time, he was started on phenytoin for seizure prophylaxis and discharged approximately 2 weeks later with oral phenytoin. Two weeks after discharge, the patient developed facial and eye swelling and was readmitted for a possible postoperative infection. He was empirically treated with flagyl, vancomycin, and ceftazidine. While hospitalized, the patient developed a new rash with high fevers, and dermatology was consulted. Dermatology was primarily concerned about a drug allergy or DRESS (most likely due to dilantin). Because the patient had no laboratory abnormalities or other signs of end-organ damage, he was treated conservatively. All medications were stopped, and he was discharged home a week later on acetaminophen, clindamycin lotion, hydroxyzine, cetirizine, and triamcinolone cream.

The patient returned to the ED 7 days later with persistent rash, itching, and fevers. He reported that for the previous several weeks, he had been having fevers (to $103^{\circ} \mathrm{F}$ ), arthralgias, and a skin eruption. On physical examination, the patient's vital signs were a heart rate of 78 beats per minute, blood pressure of $98 / 57 \mathrm{~mm} \mathrm{Hg}$, respiratory rate of 20 breaths per minute, and pulse-oximetry of $98 \%$ on room air. He was alert and oriented and in no apparent distress. He had no meningismus. Lungs were clear to auscultation. Heart 
Table. Emergency department laboratory results.

\begin{tabular}{|c|c|c|c|}
\hline & Case 1 (adult) & Case 2 (child) & Normal range \\
\hline \multicolumn{4}{|l|}{ Hematology } \\
\hline White blood cell count & 13.3 & 3.1 & $5.0-14.0 \times 1,000 / \mu \mathrm{L}$ \\
\hline Hemoglobin & 13.6 & 13.0 & $11.0-15.0 \mathrm{~g} / \mathrm{dL}$ \\
\hline Hematocrit & 39.6 & 37.4 & $35.0-43.0 \%$ \\
\hline Platelet count & 310 & 144 & $150-350 \times 1,000 / \mu \mathrm{L}$ \\
\hline Neutrophils (\%) & 66 & 46 & $35-71 \%$ \\
\hline Lymphocytes (\%) & 19 & 44 & $20-56 \%$ \\
\hline Monocytes (\%) & 8 & 9 & $2-15 \%$ \\
\hline Eosinophils (\%) & 18 & $<1$ & $0-5 \%$ \\
\hline Peripheral smear & $\begin{array}{l}\text { Few atypical } \\
\text { lymphocytes }\end{array}$ & $\begin{array}{l}\text { Microcytosis, elliptocytes, giant platelets, } \\
\text { and a few atypical lymphocytes }\end{array}$ & \\
\hline Prothrombin time & 13.6 & 16.2 & $9.7-12.1$ seconds \\
\hline Partial thromboplastin time & 28.4 & 31.1 & $22-35$ seconds \\
\hline International normalized ratio & 1.30 & 1.57 & $0.80-1.20$ \\
\hline \multicolumn{4}{|l|}{ Chemistry } \\
\hline Glucose & 91 & 83 & $70-100 \mathrm{mg} / \mathrm{dL}$ \\
\hline Blood urea nitrogen & 9 & 25 & $8-18 \mathrm{mg} / \mathrm{dL}$ \\
\hline Creatinine & 0.7 & 0.7 & $0.5-1.2 \mathrm{mg} / \mathrm{dL}$ \\
\hline $\mathrm{CO}_{2}$ & 25.8 & 19.7 & $22.0-30.0 \mathrm{mmol} / \mathrm{L}$ \\
\hline Chloride & 101 & 99 & 96-106 mmol/L \\
\hline Sodium & 139 & 133 & $135-145 \mathrm{mmol} / \mathrm{L}$ \\
\hline Potassium & 3.6 & 4.4 & $3.5-5.0 \mathrm{mmol} / \mathrm{L}$ \\
\hline Aspartate transaminase & 62 & 8,120 & $0-59 \mathrm{U} / \mathrm{L}$ \\
\hline Alanine transaminase & 296 & 4,790 & $0-34 \mathrm{U} / \mathrm{L}$ \\
\hline Alkaline phosphatase & 227 & 193 & 50-480 U/L \\
\hline Direct bilirubin & 0.19 & 0.41 & $<0.20 \mathrm{mg} / \mathrm{dL}$ \\
\hline Total bilirubin & 0.52 & 0.95 & $<1.20 \mathrm{mg} / \mathrm{dL}$ \\
\hline
\end{tabular}

examination showed regular rate and rhythm, without murmur. Neurologic examination was normal. His skin had a 2- to 8-mm erythematous maculopapular eruption, most prominent on anterior chest, back, and extremities; there were no bullae, and no mucous membrane or genital involvement. The patient's laboratory results were significant for leukocytosis with eosinophilia and atypical lymphocytes, as well as a transaminitis (Table).

Dermatology was consulted and was primarily concerned about DRESS, given his diffuse rash, persistent fevers, and laboratory abnormalities. The patient was admitted to the hospital to monitor for the development of worsening organ dysfunction, toxic epidermal necrolysis, and to initiate oral prednisone, calcium, and vitamin D. An electrocardiogram, echocardiogram, and ultrasound of the liver were performed as an inpatient and were all within normal limits.

The patient's skin symptoms and laboratory abnormalities started improving on the second day of hospitalization. He was discharged home after 3 days with a 6-week oral prednisone taper. In consultation with neurosurgery, as well as allergy and immunology specialists, antiepileptic medications were held. On discharge, the patient's rash and pruritis were significantly improved, and he has had no additional complications or subsequent hospitalizations for related issues.

\section{CASE TWO}

A 10-year-old girl appeared in the pediatric ED with a 1week history of rash and fevers. Her mother reported that 7 days before presentation, she noted the onset of a pink rash over her daughter's cheeks, which had subsequently spread over her arms, legs, trunk, and back. Initially, the rash consisted of "pink raised bumps," but during the previous 2 days had become confluent over extremities and trunk. She also had facial and lip swelling. The rash had been accompanied by fever (measured at $103^{\circ} \mathrm{F}$ ), fatigue, and lower extremity arthralgia. The child's medical history was significant for bipolar disorder, for which she had been taking divalproex (Depakote) and methylphenidate for 3 years. Eleven days before the onset of 
symptoms, the patient began taking lamotrigine for better control of bipolar symptoms.

The child's physical examination was remarkable for a fever of $104.5^{\circ} \mathrm{F}$, heart rate of 117 beats per minute, blood pressure of $104 / 50 \mathrm{~mm} \mathrm{Hg}$, respiratory rate of 20 breaths per minute, and oxygenation of $100 \%$ on room air. She was awake and alert with no acute distress, but appeared fatigued and in mild discomfort. Her skin examination was significant for pink, edematous, thin plaques with breaking up of confluent erythema into scattered thin pink papules over elbows, feet, and the perioral and periorbital regions. She had facial swelling with perioral and periorbital sparing. No mucous membrane, scleral, or genital involvement was noted. She exhibited no meningismus and had a normal heart, lung, and abdominal examination. A mildly enlarged lymph node was palpated in her left axilla. The patient's laboratory results (Table) were significant for transaminitis, elevated prothrombin time and international normalized ratio, decreased white blood cells, and atypical lymphocytes on peripheral smear (no eosinophilia was noted).

The main differential diagnoses included DRESS, serum sickness, Kawasaki disease, and sources of transaminitis, such as autoimmune hepatitis or viral infection. Dermatology was consulted in the ED. The patient's skin examination, transaminitis and recent initiation of lamotragine made DRESS the most likely diagnosis. Because the patient was nontoxic with no localizing signs of infection, she was not given empiric antibiotics in the ED (although blood and urine cultures were drawn, which later came back negative).

The patient was admitted to the hospital for initiation of oral prednisone $(1 \mathrm{mg} / \mathrm{kg})$ and monitoring for worsening liver function and development of mucous membrane involvement. Inpatient echocardiography and liver ultrasound were unremarkable. One day after admission, the patient's transaminitis was not improving; she was transferred to the pediatric intensive care unit for closer monitoring and initiation of intravenous $\mathrm{N}$-acetylcysteine (NAC).

The patient's liver-function tests started to improve on hospital day 4, and she was discharged on day 8 . Throughout her hospitalization, the patient did not receive any standing psychiatric medications. Although she did have an exacerbation of her bipolar symptoms, she was managed with haloperidol as needed. She was discharged home on no psychiatric medications, but with close monitoring from both her psychiatrist and pediatrician.

\section{DISCUSSION}

DRESS syndrome usually presents within 8 weeks of initiation of the causative medication. Aromatic anticonvulsants (phenytoin, phenobarbital, carbamazepine) are the most common cause of DRESS, but a variety of other drugs, such as allopurinol, minocycline, dapsone, sulfasalazine, and mexiletine, have also been associated with DRESS. ${ }^{1}$ The estimated occurrence of the syndrome is between 1 in 1,000 and 1 in 10,000 exposures to antiepileptic drugs. ${ }^{2}$ There is a $10 \%$ mortality rate from DRESS, mostly due to liver damage thought to be secondary to eosinophilic infiltration. ${ }^{3}$ The diagnostic criteria for DRESS syndrome include (a) widespread cutaneous eruption; (b) fever; (c) systemic involvement, including lymphadenopathy and/or 1 or more internal organ involvements (for example, interstitial nephritis, myocarditis, pericarditis, pneumonitis, hepatitis); and (d) 1 or more biologic abnormalities (for example, eosinophilia $>1,500 / \mathrm{mm}^{3}$, mononucleosis-like atypical lymphocytosis). ${ }^{3-5}$

Before the diagnosis of DRESS can be made, other diseases that may appear similar must be excluded. The differential diagnoses include drug-induced lupus erythematosus, hypereosinophilic syndrome, infectious mononucleosis, Kawasaki disease, Stevens-Johnson syndrome, toxic epidermal necrolysis, measles, pseudolymphoma, immunoblastic lymphadenopathy, serum sickness-like reaction, and staphylococcal toxic shock syndrome. ${ }^{2}$ DRESS can be particularly difficult to distinguish from infectious etiologies, and empiric antibiotics should be administered if clinically appropriate. ${ }^{6}$ Although no definitive laboratory test exists for DRESS, a complete blood cell count can identify the characteristic leukocytosis with eosinophilia, and liver-function tests, renal function, and urinalysis can help identify internal organ involvement. ${ }^{3}$ Skin biopsy is not specific. ${ }^{3}$

The exact pathophysiology of DRESS is not fully understood. Several factors have been associated with the development of DRESS, including a decrease in serum immunoglobulin and circulating B cells. ${ }^{7,8}$ It is unclear whether these factors are preexisting or are induced by the medications involved in DRESS. The long latency period between medication administration and DRESS occurrence may represent the time required for these effects to take place. In addition, a connection between DRESS and human herpes virus (HHV-6) reactivation has been suggested. However, because reactivation of HHV-6 is not universal among DRESS syndrome patients, they have been separated into a different clinical entity known as drug-induced hypersensitivity syndrome., ${ }^{9,10}$

The major consequences of DRESS include skin rash (that may progress to exfoliative dermatitis), fever,

lymphadenopathy, and damage to viscera. The organ systems most often affected are liver, kidneys, lungs, and heart (in the form of pericarditis or myocarditis). ${ }^{3}$ In approximately $50 \%$ of patients, hepatitis develops, $10 \%$ develop nephritis, and $10 \%$ develop pneumonitis. ${ }^{6}$ Hepatic necrosis is the major contributor to death, with mortality as high as $40 \%$ in these patients. ${ }^{11}$

Discontinuation of the offending drug is the primary treatment of DRESS. Antipyretics may also be used to control fever. The use of systemic corticosteroids is controversial, as no randomized, controlled clinical trials currently exist. ${ }^{1,12}$ Steroid treatment must be weighed carefully because steroids may prolong wound healing, increase risks of infection, precipitate gastrointestinal bleeding, and mask early signs of sepsis. ${ }^{3} \mathrm{NAC}$ 
has been proposed as a potential therapy because of its role in drug detoxification. It was used in the pediatric patient, given her increasing liver-function tests and the NAC low-risk profile. However, currently insufficient randomized controlled data exist to support or oppose NAC use for DRESS syndrome. ${ }^{13}$

The prognosis of DRESS is generally favorable if the syndrome is recognized and the offending medication is stopped before significant visceral involvement has occurred. ${ }^{5}$ The cutaneous manifestations may persist for several weeks, and have been known to recur if systemic corticosteroids are tapered too quickly or with re-exposure to the offending agent. ${ }^{5}$

\section{CONCLUSION}

DRESS is a potentially life-threatening adverse drug reaction that appears with diffuse skin rashes, fever, and internal organ involvement. DRESS can lead to significant morbidity and mortality, but can often be treated by discontinuing the offending agent and oral steroids. Emergency physicians should consider DRESS in their differential diagnosis of adult and pediatric patients with diffuse maculopapular rash and systemic symptoms.

\section{ACKNOWLEDGMENTS}

We thank Andrew Meiman, PA-C and the Yale-New Haven Hospital dermatology consult service for their assistance in caring for these patients.

Address for Correspondence: Alina Tsyrulnik, MD, Yale University School of Medicine, Department of Emergency Medicine, 464 Congress Ave, Ste 260, New Haven, CT 06519. E-mail: alina.tsyrulnik@yale.edu.

Conflicts of Interest: By the WestJEM article submission agreement, all authors are required to disclose all affiliations, funding sources, and financial or management relationships that could be perceived as potential sources of bias. The authors disclosed none.

\section{REFERENCES}

1. Ghislain PD, Roujeau JC. Treatment of severe drug reactions: StevensJohnson syndrome, toxic epidermal necrolysis and hypersensitivity syndrome. Dermatol Online J. 2002;8:5.

2. Gennis MA, Vemuri R, Burns EA, et al. Familial occurrence of hypersensitivity to phenytoin. Am J Med. 1991;91:631-634.

3. Tas S, Simonart T. Management of drug rash with eosinophilia and systemic symptoms (DRESS syndrome): an update. Dermatology. 2003;206:353-356.

4. Tas $S$, Simonart T. Drug rash with eosinophilia and systemic symptoms (DRESS syndrome). Acta Clin Belg. 1999;31:54-64.

5. Bocquet H, Martine B, Roujeau JC. Drug-induced pseudolymphoma and drug hypersensitivity syndrome (drug rash eosinophilia and systemic symptoms: DRESS). Semin Cutan Med Surg. 1996;15:250-257.

6. Rosenbaum J, Alex G, Roberts $\mathrm{H}$, et al. Drug rash with eosinophilia and systemic symptoms secondary to sulfasalazine. J Paediatr Child Health. 2009;46:193-196.

7. Kano Y, Seishima M, Shiohara T. Association between anticonvulsant hypersensitivity syndrome and human herpesvirus reactivation and hypogammaglobulinemia. Arch Dermatol. 2004;140:183-188.

8. Kano Y, Seishima M, Shiohara T. Hypogammaglobulinemia as an early sign of drug-induced hypersensitivity syndrome. J Am Acad Dermatol. 2006;55:727-728.

9. Hashimoto K, Yasukawa M, Tohyama M. Human herpesvirus 6 and drug allergy. Curr Opin Allergy Clin Immunol. 2003;3:255-260.

10. Shiohara $T$, ligima $M$, Ikezawa $Z$, et al. The diagnosis of DRESS syndrome has been sufficiently established on the basis of typical clinical features and viral reactivation. Br J Dermatol. 2007;156:10831084.

11. Dhar GJ, Ahamed PN, Pierach CA. Diphenylhydantoin-induced hepatic necrosis. Postgrad Med. 1974;56:128-134.

12. Chapman MS, Zug KA, Dewis LD. Lamotrigine and phenobarbitoneassociated hypersensitivity syndrome: resolution without corticosteroids. Br J Dermatol. 1998;138:710-711.

13. Redondo R, De Felipe I, de la Pena, et al. Drug-induced hypersensitivity syndrome and toxic epidermal necrolysis: treatment with $\mathrm{N}$ acetylcysteine. Br J Dermatol. 1997;136:645-646. 